\title{
Optimal sizing and location of distributed generation for loss minimization using firefly algorithm
}

\author{
Muhamad Najib Kamarudin, Tengku Juhana Tengku Hashim, AbdulHamid Musa \\ Department of Electrical Power Engineering, Universiti Tenaga Nasional, Malaysia
}

\begin{tabular}{l} 
Article Info \\
\hline Article history: \\
Received Oct 1, 2018 \\
Revised Nov 20, 2018 \\
Accepted Dec 15, 2018 \\
\hline
\end{tabular}

\section{Keywords:}

Distributed generation

Firefly algorithm

IEEE 33-bus distribution

system

Optimization

Power losses

\begin{abstract}
Distributed generation (DG) plays an important role in improving power quality as well as system realibility. As the incorporation of DG in the power distribution network creates several problems to the network operators, locating a suitable capacity and placement for DG will essentially help to improve the quality of power delivery to the end users. This paper presents the simulation of an application of firefly algorithm (FA) for optimally locating the most suitable placement and capacity of distributed generation (DG) in IEEE 33-bus radial distribution network. This strategy aims at minimizing losses together with improving the voltage profile in distribution network. The losses in real power and voltages at each bus are obtained using load flow analysis which was performed on an IEEE 33-bus radial distribution network using forward sweep method. The proposed method comprises of simulation of the test system with DG as well as in the absence of DG in the system. A comparison between the Firefly Algorithm (FA) with Genetic Algorithm (GA) is also demonstrated in this paper. The results obtained have proven that the Firefly Algorithm has a better capability at improving both the voltage profile and the power losses in the system.
\end{abstract}

Copyright $@ 2019$ Institute of Advanced Engineering and Science. All rights reserved.

\section{Corresponding Author:}

Tengku Juhana Tengku Hashim,

Department of Electrical Power Engineering,

Universiti Tenaga Nasional (Putrajaya Campus),

KM-7 Jalan IKRAM-UNITEN, 43009, Kajang, Selangor, Malaysia.

Email: juhana@uniten.edu.my

\section{INTRODUCTION}

In a distribution network, the distributed generation are used for several purposes, for instance reducing power losses, obtaining better voltage profile along the feeders, as well as to maximize the increment of transmitted power in transformers and cables. For power loss reduction, the distributed generation which have been installed in power distribution systems are used for compensation of reactive power. However, the distributed generation (DG) installation in distribution systems requires consideration of their suitable placement and sizing for distributed generation. The main objective of this work is to find the optimal location and sizing of the distributed generation for in order to minimize the losses of real power and also for the improvement of voltage profile. However, the installation of distributed generation units at nonoptimal locations and also non-optimal size can causes several problems such as voltage flicker, damaging the voltage state, system losses, harmonics and power system stability which it can lead to an increase in operational costs [1-2].

Therefore, the optimization method used in recent studies shows that it is able of showing the suitable answer for a particular distribution system can be very suitable in power system development. Studies shown that, various optimization method have been created for solving the ideal capacity and placement of distributed generation in the distribution networks. The optimization technique included such as genetic algorithm, tabu search, heuristic algorithms [3], analytical based methods [2] and metaheuristic 
algorithms which were developed based on swarm intelligence in natural world such as Particle Swarm Optimization (PSO), Ant Colony Optimization as well as Artificial Bee Algorithm techniques [4]. There have been numerous work carried out by researchers worldwide in the area of locating the optimal capacity and placement of DG using all these optimization techniques. In the work done in [12], the optimal size and location of DG was carried out on an IEEE 69 bus test system and it was found out that the Firefly Algorithm was able to minimize the total power losses in the system. In another work, the optimal allocation of several DGs utilizing a combination of analytical and genetic algorithm methods to minimize the system losses was compared using the 33-bus and 69-bus IEEE test distribution systems. The simulation results show that the proposed method resulted in lower power losses obtained [13]. Other than that, in the work done in [14], a method known as gravitational search algorithm (GSA) was used to minimize the losses and total harmonic distortion in the system while locating the suitable placement and sizing of DG. The results have shown that GSA performs better than PSO in having better convergence rate and fitness function as well as minimizing losses in the system. On the other hand, the optimal location, sizing, and contract pricing of DG in electric distribution systems were found using three optimization methods of Scatter Search, GA and PSO. It was found that that GA and PSO performed better in solving the multiobjective problem [15].

In this research work, the voltage and system losses analyzation with the incorporation of distributed generation (DG) in the system is carried out using a metaheuristic optimization technique known as the Firefly Algorithm. This algorithm which is inspired by nature and it is a metaheuristic optimization technique which works based on the public (sparkling) nature of fireflies. Fireflies are considered by their flashing light created by natural activity known as bioluminescence. In this cases, the flashing of light may perform as the key of courtship signals for mating with other fireflies and also be used for giving a warning to potential predators. This flashing light will be connected with the objective function to be improved, which will create the potential to express new optimization algorithm [5].

This paper presents a simulation of load flow analysis of an IEEE 33-bus radial distribution network for finding the losses of power and voltage improvement. The data for IEEE 33-bus distribution network is taken from [11]. In this study, the firefly algorithm (FA) has been proposed in order to determine the best answer for the ideal allocation and size of distributed generation (DG) in an IEEE 33-bus distribution test network. The simulation of the test system was carried out in MATLAB software. The paper is structured as follows in which Section 2 presents the problem formulation for this work, the optimization algorithm and methodology for the firefly algorithm. Next, the results and discussion obtained from the simulation work is discussed in Section 3. Lastly, in Section 4, the conclusions from the research work is presented.

\section{PROBLEM FORMULATION}

In this paper, the main objective function of this optimization problem is aimed at obtaining loss minimization and improvement of voltage profile. As the losses is minimized, the voltage profile at every bus is estimated to be improved. The equations of the optimal location of distributed generation is stated as below:

$$
x=\left[x_{1 L}, x_{1 S}, \ldots x_{n L}, x_{n L}\right]
$$

where $\mathrm{S}$ shows the size of distributed generation while $\mathrm{L}$ shows the location of distributed generation and $\mathrm{n}$ is the number of distributed generation component that will be connected in the network. Equation (1) is included in the load flow data and then it is executed for obtaining the total losses in the system. The objective function, $\mathrm{f}(\mathrm{x})$ is the outcome of the sum of losses in the network as the Ploss is minimized. The following equation is formulated based on equation (1) which is the objective function for this work:

$$
f(x)=\min \left(\sum_{j=1}^{\text {line }} \text { Ploss }\right)
$$

where line is referred to number of lines in the distribution network. Ploss can be obtained by using equation (3) and is also based on the parameters in equation (1).

$$
\text { Ploss }=\sum_{i=1}^{N} \sum_{j=1}^{N}\left[\alpha_{i j}\left(P_{i} P_{j}+Q_{i} Q_{j}\right)-\beta_{i j}\left(Q_{i} P_{j}-P_{i} Q_{j}\right)\right]
$$

For this research work, firefly algorithm has been introduced as an application for solving the ideal placement and capacity of distributed generation problems. As mentioned in the introduction, firefly algorithm is one of the swarm based optimization algorithm where it is performing based on the sparkling performance of all the fireflies. The steps or description of all parameters required in modelling the algorithm for finding the ideal size and location of distributed generation is presented below. Based on the founder of 
firefly algorithm, he stated that [5]:

1. A single firefly will be lured to other fireflies according to their sex even though there are unisex.

2. The brightness is proportional to their attractiveness. Therefore the firefly which is less bright will move towards the brighter firefly. As there are proportional to each other, their attractiveness will decrease as their distance increases. Hence, fireflies will move randomly if there is no brighter firefly.

3. The landscape of the objective function will determine the brightness of a firefly

It can be assumed that the attractiveness of a firefly is observed with its brightness where it is related to the objective function. For the simple case of the maximum optimization problems, the attraction which is ' $\beta$ ' is virtual where it can be seen in the eyes of the other fireflies. Hence, the distance $r_{i j}$ will be exchanged with firefly ' $j$ ' and firefly ' $i$ ' [5]. There are three important elements that have one has to follow in order to find the optimal placement and sizing of distributed generation in the network using firefly algorithm. The parameters were selected for simulation when using the firefly algorithm technique. These include the attractiveness $\beta_{0}=1.0, \alpha \in[0,1]$ and the attractive quality or the ingestion coefficient $\gamma=1.0$, which are used to ensure a rapid interaction of firefly algorithm for the calculation to the ideal solution.

\subsection{Attractiveness}

In the firefly algorithm, the application of the formulation of attractiveness and light intensity is very important in this algorithm. Light strength is proportional to the attraction of all the fireflies and therefore, the attractiveness function is stated as follows:

$$
\mathrm{B}_{\mathrm{r}}=\mathrm{B}_{0} * \exp \left(-\gamma_{i j}^{m}\right), \text { with } m \geq 1
$$

where, $B_{0}$ is the attractiveness at $r=0$ while $r$ is the separation between several fireflies. Furthermore, $\gamma$ is an ingestion of constant which dominates the diminishing of light power.

\subsection{Distance}

A Cartesian equation is taken after deciding the separation between any two fireflies $\mathrm{i}$ and $\mathrm{j}$, at positions $X_{i}$ and $X_{j}$ :

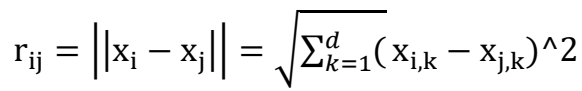

where $d$ is the quantity of measurements, for $d=2$, and $x_{i k}$ is the kth part of the spatial arrange $x_{i}$ of the ith firefly. Therefore, $r_{i j}$ which is given as:

$$
r_{i j}=\sqrt{\left(x_{i}-x_{j}\right)^{2}+\left(y_{i}-y_{j}\right)^{2}}
$$

Moreover, the computation of the separation of $r$ can likewise be characterized by utilizing other separation measurements which depends on the idea of the issue for instance Mahalanobis separation or Manhattan distance.

\subsection{Movement}

The firefly movement $\mathrm{j}$ which is interested by a more attractive or the brighter firefly $\mathrm{i}$ is given by the stated formulation below:

$$
\mathrm{x}_{\mathrm{i}}=\mathrm{x}_{\mathrm{i}}+\beta_{0} * \exp \left(-\gamma_{i j}^{2}\right) *\left(\mathrm{x}_{\mathrm{j}}-\mathrm{x}_{\mathrm{i}}\right)+a *\left(\operatorname{rand}-\frac{1}{2}\right)
$$

A procedure for implementing the firefly algorithm with the load flow analysis of IEEE 33-bus radial distribution network in order to find the optimal location and sizing of distributed generation in the system are summarized in Figure 1. After all the solutions are obtained, the results are discussed in part 3. 


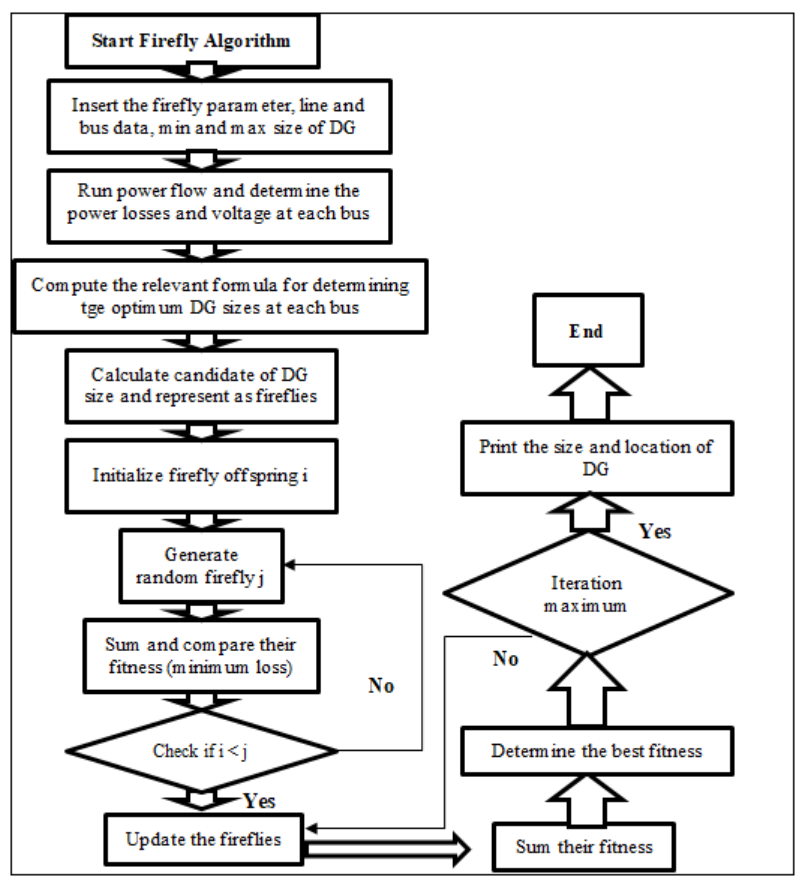

Figure 1. Flowchart for finding the of ideal sizing and location of DG using firefly algorithm

\section{RESULTS AND ANALYSIS}

The six firefly algorithm parameters variable values used are given below in Table 1. The simulation study was carried out by determining the system loading condition. The IEEE 33-bus system selected for base $\mathrm{kV}$ and MVA is $12.66 \mathrm{kV}$ and 100MVA. The data for the line and load for the IEEE 33-bus system was taken from MATPOWER 6.0. The test system incorporated with the optimization algorithm had been simulated on MATLAB R2018a software and run on MACBOOK with IOS operation system. Figure 2 below shows the 33-bus radial distribution network. The sum of the load of the network is $3.72 \mathrm{MW}$ for the active power and 2.3 MVAR for the reactive power while the active power loss is $281.58 \mathrm{~kW}$.

Table 1. The Firefly Algorithm Properties Used In the Optimization Formulation

\begin{tabular}{l|l}
\hline Firefly Algorithm Parameters & Values \\
\hline Population of Firefly & 20 \\
\hline Highest number of iteration & 30 \\
\hline Number of DG & 1 and 2 \\
\hline Capacity of DG & $0.01 \mathrm{MW}$ to 5MW \\
\hline Alpha & 0.25 \\
\hline Beta & 0.2 \\
\hline
\end{tabular}

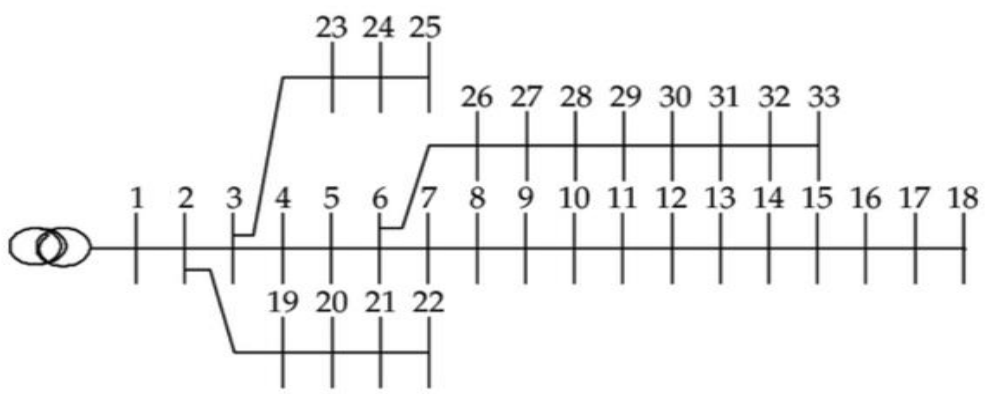

Figure 2. The IEEE 33-Bus radial distribution network 
To further investigate the effectiveness of the firefly optimization algorithm in finding the ideal sizing and location of the distributed generations, the following three cases are simulated:

Case 1: Simulation of the system without DG, to determine the base case scenario.

Case 2: Simulation of the system with one DG included.

Case 3: Simulation of the system with two DGs included.

In order to show the advantages of using firefly algorithm, the three simulation cases are also carried out using another optimization method which is Genetic Algorithm. Table 2 below shows the outcomes of the simulation of the power flow of IEEE 33-bus distribution network using the MATLAB software integrated with the optimization algorithm for finding the optimal sizing and placement of the distributed generation using the two optimization algorithms.

Table 2. Comparisons of Results between Firefly Algorithms with Genetic Algorithm for the Three Case Studies

\begin{tabular}{cccccc}
\hline & & $\begin{array}{c}\text { Total Real Power } \\
\text { losses } \\
\text { (MW) }\end{array}$ & $\begin{array}{c}\text { Bus voltage } \\
\text { Bus number }\end{array}$ & $\begin{array}{c}\text { Minimum bus } \\
\text { Voltage (p.u) }\end{array}$ & $\begin{array}{c}\text { Optimal size } \\
\text { and location } \\
\text { Size (MW) }\end{array}$ \\
\hline Case 1(without DG) & & 0.193 & 18 & 0.8820 & - \\
Location
\end{tabular}

Based on the results obtained from Case 2 which is by connecting one distributed generation into the system, the network losses recorded is $0.178 \mathrm{MW}$ and the minimum bus voltage obtained is $0.9034 \mathrm{~V}$. This power loss result is better than Case 1 which is the base case where in the base case, the total real power loss obtained was $0.193 \mathrm{MW}$. The simulation also shows that after installing a single distributed generation into the system, the optimal location recorded is at bus number 7 and the optimal sizing of the DG is 1.5214 MW. Case 3 considered connecting two distributed generations into the network and the network losses recorded is $0.134 \mathrm{MW}$ and the minimum bus voltage obtained is $0.9371 \mathrm{~V}$. It can also be seen that the suitable locations after installing two distributed generations are at bus number 7 and 27 with the appropriate size of 0.5645 MW and 2.0968 MW. It can be seen from the results obtained using Genetic Algorithm (GA), the ideal placement of distributed generation is similar to the ones obtained using firefly algorithm. For case 2, the optimal location obtained using GA for installing the DG is obtained to be at bus 7 and for case 3 the ideal placements obtained are at buses 7 and 27 respectively.

The total real power losses recorded by firefly algorithm is better than achieved by using genetic algorithm for all the three case studies. In case 2, by installing one DG in the system, it can be seen that the total real power loss is reduced by $7.8 \%$ compared to the base case without distributed generation installation. Next, for case 3 , reduction on the total real power losses obtained is $30.6 \%$ compared to the base case. The calculations for obtaining the percentage of reduction of power loss is shown next:

$(1 \mathrm{DG})-$ Real power losses $=(0.193-0.178) / 0.193 \times 100 \%=7.8 \%$

$(2$ DGs $)-$ Real power losses $=(0.193-0.134) / 0.193 \times 100 \%=30.6 \%$

Figures 3 and 4 below shows the voltage profile obtained with and without the inclusion of DG in the system. It is seen in Figure 4 that with the installation of DGs, the voltage profile is better and the curve is within the optimal value of 1.0 p.u. 


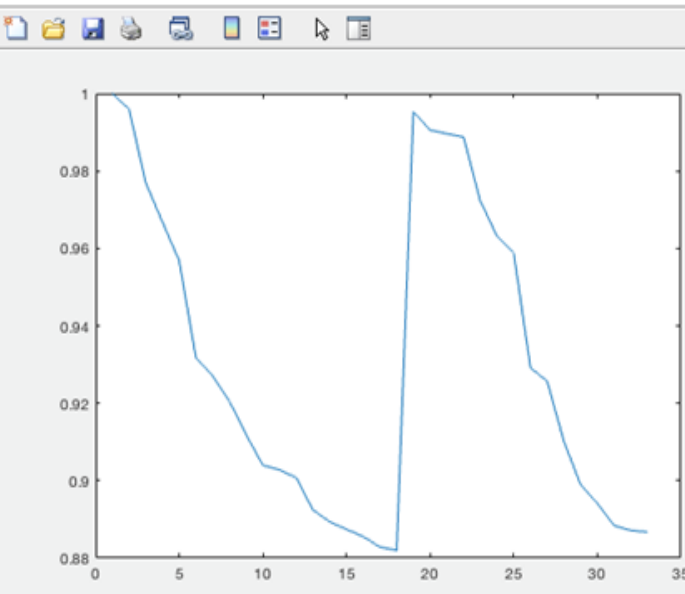

Figure 3. Voltage profile without DG included in the system

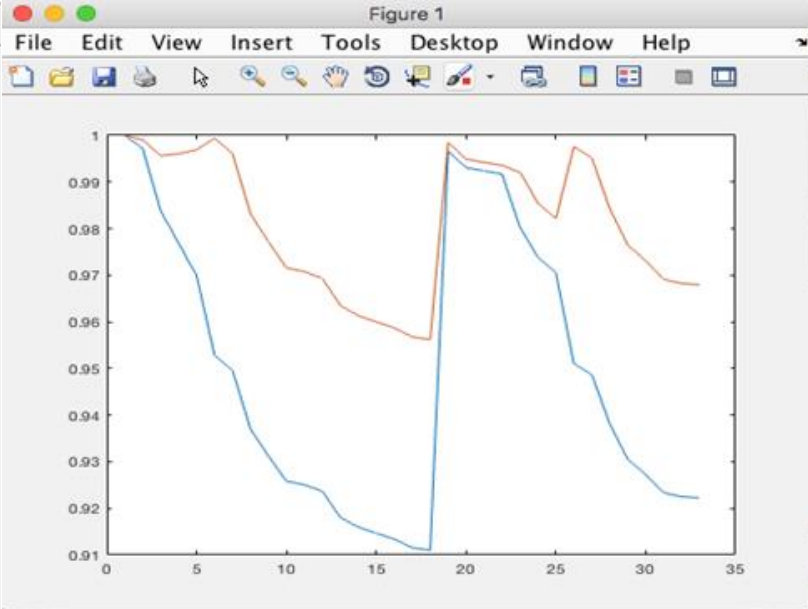

Figure 4. Voltage profile with one and two DGs included in the system

\section{CONCLUSION}

This paper has presented the implementation of firefly optimization algorithm in finding the most suitable placement and capacity of DG when DG is incorporated in the system. It can be seen from the results obtained, the firefly algorithm is better compared to another well known optimization method of genetic algorithm (GA) for determining the optimal placement and capacity of distributed generations in the distribution system. The results show that integrating the distributed generation with the optimal capacity and the suitable placement in the distribution network is able to reduce the sum $\mathrm{S}_{\mathrm{f}}$ line power losses and the improvement of voltage profile. It is also seen that the total power losses and the total voltage deviation of the network is better with the integration of two DGs compared to the case with one DG. It is suggested that for future work, an improvement in the problem formulation and objective function could be achieved. In conclusion, the metaheuristic Firefly Algorithm (FA) has shown to be promising in determining the optimal placement and capacity of the distributed generation while minimizing the total real power loss and improving the voltage profile.

1 DG

\section{ACKNOWLEDGEMENT}

The authors would like to express their gratitude to Universiti Tenaga Nasional (UNITEN) for providing the funding for this research and acknowledges the UNITEN Internal Grant (UNIIG) Project Code J510050699.

\section{REFERENCES}

[1] R. Sirjani, A. Mohamed, H. Shareef, "Heuristic optimization techniques to determine optimal capacitor placement and sizing in radial distribution networks", Przegląd Elektrotechniczny (Electrical Review), Issn 0033-2097, r. 88 nr $7 \mathrm{a} / 2012$.

[2] O. Amanifar ,M.E. Hamedani Golshan," Optimal distributed generation placement and sizing for loss and THD reduction and voltage profile improvement in distribution systems using particle swarm optimization and sensitivity analysis", International Journal on Technical and Physical Problems of Engineering (IJTPE), Iss. 7, Vol. 3, No. 2, Jun. 2011.

[3] T. Inoue, K. Takano, T. Watanabe, J. Kawahara, R. Yoshinaka, A. Kishimoto, K. Tsuda, S. Minato, Y. Hayashi,"Loss Minimization of Power Distribution Networks with Guaranteed Error Bound”, Hokkaido University Graduate School of Information Science and Technology, Division of Computer Science Report Series A August 21, 2012.

[4] Sh. M. Farahani, A. A. Abshouri, B. Nasiri, and M. R. Meybodi, "A Gaussian Firefly Algorithm”, International Journal of Machine ispeplearning and Computing, Vol. 1, No. 5, December 201.

[5] X.-S. Yang, "Firefly algorithms for multimodal optimization,"Stochastic Algorithms: Foundation and Applications SAGA 2009, vol.5792, pp. 169-178, 2009.

[6] M. H. Sulaiman, M.W. Mustafa.; A. Azmi; O. Aliman; S. R. Abdul Rahim; "Optimal Allocation and Sizing of Distributed Generation in Distribution System via Firefly Algorithm" Power Engineering and Optimization Conference (PEDCO) Melaka, Malaysia, 2012, pp. 84-89. 
[7] P. P. Barker, R. W. de Mello; "Determining the Impact of Distributed sispeneration on Power Systems: Part 1Radial Distribution Systems", IEEE PES Summer Meeting, 2000, Vol.3, pp.1645-1656.

[8] X. Yang, Nature-inspired Metaheuristic Algorithms: Luniver Press, 2008.

[9] M. K. Sayadi, R. Ramezanian, and N. Ghaffari-Nasab, "A discrete firefly meta-heuristic with local search for makespan minimization in permutation flow shop scheduling problems," International Journal of Industrial

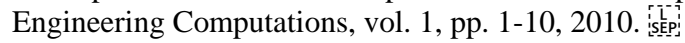

[10] D. Goldberg and J. Holland, "Genetic Algorithms and Machine Learning," Machine Learning, vol. 3, pp. 95-99, 1988.

[11] Mohammad Salehi Maleh1, Ramtin Rasouli Nezhad2 and Noradin Ghadimi3, "Placement of distributed generation units using multi objective function based on SA algorithm", Vol. 8(31),pp.1471- 1477,18August,2013DOI 10.5897 / ISSN 1992-2248 (C) 2013.

[12] K. Nadhir, D. Chabane, and B. Tarek, "Firefly Algorithm for Optimal Allocation and Sizing of Distributed Generation in Radial Distribution System for Loss Minimization," 2013 International Conference on Control, Decision and Information Technologies (CoDIT), pp. 231 - 235, 2013.

[13] M. Vatani, D. S. Alkaran, M. J. Sanjari, and G. B. Gharehpetian, "Multiple distributed generation unit allocation in distribution network for loss reduction based on a combination of analytical and genetic algorithm methods," IET Generation, Transmission \& Distribution, pp. 1-7, 2015.

[14] Aida Fazliana Abdul Kadir, Azah Mohamed, Hussain Shareef, Mohd Zamri Che Wanik, Ahmad Asrul Ibrahim, "Optimal sizing and placement of distributed generation in distribution system considering losses and THDV using gravitational search algorithm,” Journal of Przeglad Elektrotechniczny, pp 132-136, 2013.

[15] A. Pérez Posada, J. Villegas, and J. López-Lezama, "A Scatter Search Heuristic for the Optimal Location, Sizing and Contract Pricing of Distributed Generation in Electric Distribution Systems," Energies, vol. 10, no. 10, 2017.

\section{BIOGRAPHIES OF AUTHORS}
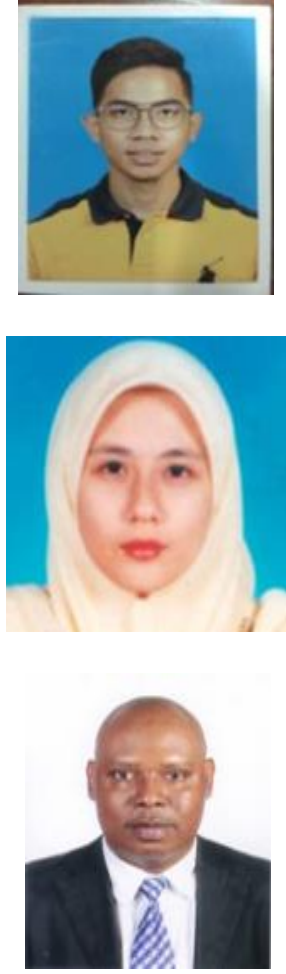

Muhamad Najib bin Kamarudin was born on $12^{\text {th }}$ April 1995 at Assunta Hospital, Petaling Jaya, Malaysia. He is currently living in Bandar Baru Bangi, Selangor. He earned his Bachelor's Degree in Electrical Power Engineering from Universiti Tenaga Nasional (UNITEN) in 2018. His current research interests includes power quality and optimization in power system analysis.

Tengku Juhana Tengku Hashim was born in Kuantan, Pahang, Malaysia in May 1979. She received her B. Eng in Electrical Power Engineering in 2002 and Masters in Electrical Engineering in 2004 from Universiti Tenaga Nasional (UNITEN), Selangor, Malaysia. She obtained her $\mathrm{PhD}$ in Electrical, Electronics and Systems Engineering from Universiti Kebangsaan Malaysia (UKM), Bangi Malaysia in 2014 specializing in the area of optimization of voltage control methods in an active distribution system. She is currently Her current research interests includes power quality and optimization in power system analysis.

Abdulhamid Musa was born in Zaria, the Kaduna state of Nigeria in March 1971. He obtained Bachelor's degree in electrical engineering in 1996 and is currently a Masters student of Electrical Engineering in Universiti Tenaga Nasional (UNITEN), Malaysia. His current research work is on optimization in electrical power system. 